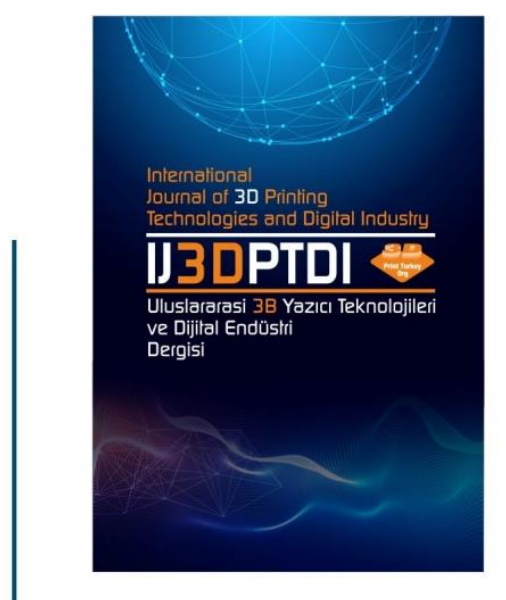

ULUSLARARASI 3B YAZICI TEKNOLOJILERI

VE DIJITAL ENDÜSTRI DERGISI

INTERNATIONAL JOURNAL QF 30 PRINTING TECHNOLOGIES AND DIGITAL INDUSTRY

ISSN:2602-3350 [Online]

URL: https://dergipark.org.tr/ij3dptdi

\title{
EXAMINATION OF THERMAL STRESSES OCCURRING IN CIRCULAR DISCS BY FINITE ELEMENT METHOD
}

Yazarlar (Authors): Hüseyin Fırat Kayiran*(iD

Bu makaleye şu şekilde atıfta bulunabilirsiniz (To cite to this article): Kayiran H.F. "Examination Of Thermal Stresses Occurring In Circular Discs By Finite Element Method" Int. J. of 3D Printing Tech. Dig. Ind., 5(2): 259-270, (2021). 


\title{
EXAMINATION OF THERMAL STRESSES OCCURRING IN CIRCULAR DISCS BY FINITE ELEMENT METHOD
}

\author{
Hüseyin Fırat Kayiran ${ }^{* *}(\mathbb{D})$ \\ a Agriculture and Rural Development Support Institution, Mersin Provincial Coordinator, 33140, \\ Mersin/TURKEY \\ *Correponding Author: huseyinfirat.kayiran@tkdk.gov.tr
}

(Received: 20.06.2021; Revised: 10.08.2021; Accepted: 27.08.2021)

\begin{abstract}
In this study, thermal stress analysis on discs consisting of two different materials was analyzed analytically. Disc materials were selected SiC/6061 Al Alloy composite and Al-7075 respectively. Assuming that the elasticity module does not change with temperature, thermal stress analysis was performed under constant temperature distributions in the area from the inner surface of the disc to the outer surface. Thermal stress analysis was performed under constant temperature distribution. A computer program was developed for the calculation and the ANSYS finite element program was used. The values obtained from the analysis are presented in tables and graphs. There have been differences in radial and tangential stresses that occur because the elasticity modules and thermal expansion coefficients of the materials that make up the discs are different. The radial stress value has always been determined as zero on the innermost and outermost surfaces of the discs. Tangential stresses under constant temperature distribution from the inner surface to the outer surface occurred as pressure on the inner part of the disc and tensile stress on the outer part. It is concluded that the stresses occurring in the $\mathrm{SiC} / 6061 \mathrm{Al}$ alloy composite material are greater than those of AL-7075.
\end{abstract}

Keywords: SiC-6061 Al Alloy composite disc. Aluminum Al7075 disc. Thermal stress analysis. Modulus of elasticity. ANSYS.

\section{INTRODUCTION}

Temperature is one of the situations that significantly affects the character of the material and it is necessary for researchers to work continuously. Discs are generally used in many areas such as unmanned aerial vehicles, aircraft, air vehicles, heavy industry, construction machinery, cranes, and vehicle discs. Aluminum-based metal matrix composite (MMC) materials are used in the design of land transport vehicles and aircraft structures due to their light weight and high strength-to-weight ratio [1]. $\mathrm{SiC}-6061 \mathrm{Al}$ alloy composite discs have excellent mechanical properties and high fatigue strength [2]. Studies on discs are found in the literature. Studies on discs modeled from different materials are available in various publications and books. In a study, stress analysis was performed on the rotating disc with a constant surface speed. The stresses resulting from the problem are obtained for different values of the surface velocity [3].

In one of two different studies; the stresses occurring in a boron carbide $\left(\mathrm{B}_{4} \mathrm{C}\right)$ material disc were analyzed by taking different temperatures from each other. In another study, discs with aluminum (A12024-T3) - Boron Carbide $\left(\mathrm{B}_{4} \mathrm{C}\right)$ material of different diameter sizes were modeled. Radial and tangential stresses were determined. The findings were shared with the literature [4-5]. In a different study, elastic stresses occurring on a thermoplastic disc reinforced with steel wires were investigated [6].

In a different study, stresses occurring in rotating discs with functionally rated materials of varying parabolic thickness were investigated [7].In another study, stresses were determined by applying pressure to a disc with isotropic material [8].In another study, Elasto-plastic stress analysis of thermoplastic material disc rotating at high temperatures was examined [9].Engineering and Mechanical 
Engineering in the field of mechanical problems, the design of the model and the strength analysis of parts in different loading states of certain geometry can be done. Materials that can work safely in various loading and environmental conditions on machine parts can be produced at minimum cost. For this reason, it is very important to know in advance the case of materials against temperature. [10]. In a different study; Based on Mindlin's theory, the stresses occurring in thermoelastic rotating discs have been investigated [11].

At this study, stresses and displacements in the discs with Al-7075 and SiC-6061 Al alloy composite material, which are highly preferred in the airway, aerospace industry, railway industry and aircraft industry, were determined. In this study, thermal stress analysis was performed on the single material disc. The solution has been made for two separate discs. First, all of the discs were selected as SiC-6061 Al Alloy composite. SiC-6061 Al Alloy composite materials exhibit good ductility and low density, as well as high strength and Young modulus.

Aluminium alloy based metal matrix composites mainly automobiles, aircraft, aerospace components, Marine fittings, Shipping and other industries are preferred. These materials are highly advantageous due to their excellent wear resistance, light weight, higher strength and durability. It consists of Aluminum A17075 material. Aluminum Al7075 materials are used in aerospace and automotive industries due to their high toughness and tensile strength. It is necessary to examine the behavior of these materials against temperature.

\section{MATERIAL AND METHODS}

In this study, stresses and radial displacements occurring at $15^{\circ} \mathrm{C}, 30^{\circ} \mathrm{C}, 45^{\circ} \mathrm{C}, 60^{\circ} \mathrm{C}, 75^{\circ} \mathrm{C}$ were determined in discs under constant temperature distribution. As shown in Figure 1, the inner radius of the disc is modeled as $20 \mathrm{~mm}$ and the outer radius as $40 \mathrm{~mm}$.

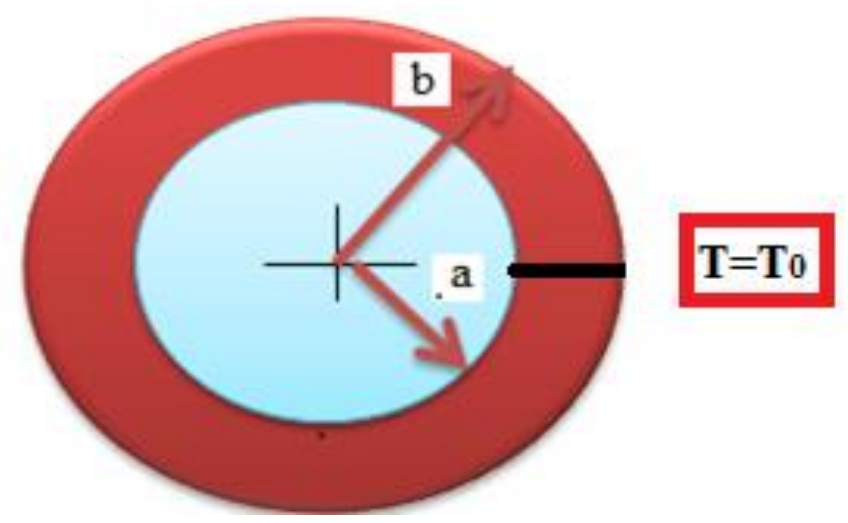

\subsection{Analytical Solution}

Figure 1. A disc modeled.

For a thin disc $\sigma_{\mathrm{z}}=0$ general equilibrium equation [12].

$$
\frac{\mathrm{r}\left(\mathrm{d} \sigma_{\mathrm{r}}\right)_{\mathrm{i}}}{\mathrm{dr}}+\left(\sigma_{\mathrm{r}}\right)_{\mathrm{i}}-\left(\sigma_{\theta}\right)_{\mathrm{i}}=0 \quad(\mathrm{i}=1)
$$

In equation (1), $\mathrm{r}$ is the radius of the disc at any point, $\sigma_{\mathrm{ri}}$ is the radial stress, and $\sigma_{\theta}$ is the tangential stress. Here the disc material is taken as $\mathrm{i}=1$.

$$
\begin{gathered}
\varepsilon_{\mathrm{ri}}=\frac{\mathrm{du}}{\mathrm{dr}} \\
\varepsilon_{\theta i}=\frac{\mathrm{u}}{\mathrm{r}}
\end{gathered}
$$


Where $\mathrm{u}$ is the displacement in the radial direction, $\varepsilon_{\mathrm{r}}$ stands for radial strain, $\varepsilon_{\theta}$ refers to the tangential strain, Strain-stress relationship;

$$
\begin{gathered}
\varepsilon_{r i}=\frac{1}{E_{i}}\left(\sigma_{r i}-v_{i} \sigma_{\theta i}\right)+\alpha_{i} T_{r} \\
\varepsilon_{\theta i}=\frac{1}{E_{i}}\left(\sigma_{\theta i}-v_{i} \sigma_{r i}\right)+\alpha_{i} T_{r} \\
\varepsilon_{r i}=\frac{1}{E_{i}}\left(\frac{F}{r}-v_{i} \frac{d F}{d r}\right)+\alpha_{i} T_{r} \\
\varepsilon_{\theta i}=\frac{1}{E_{i}}\left(\frac{d F}{d r}-v_{i} \frac{F}{r}\right)+\alpha_{i} T_{r}
\end{gathered}
$$

Obtained. The fitness equation for elongation;

$$
\mathrm{r} \frac{\mathrm{d} \varepsilon_{\theta i}}{\mathrm{dr}}+\varepsilon_{\theta \mathrm{i}}-\varepsilon_{\mathrm{ri}}=0
$$

The equilibrium equation where the stress function can be defined as $\mathrm{F}$ and equations between (1-8) are used to obtain the general equation (9).

$\mathrm{T}_{0}$ is substituted for $\mathrm{T}$;

$$
\mathrm{r}^{2} \frac{\mathrm{d}^{2} \mathrm{~F}}{\mathrm{dr^{2 }}}+\mathrm{r} \frac{\mathrm{dF}}{\mathrm{dr}}-\mathrm{F}=-\mathrm{r}^{2} \alpha_{\mathrm{i}} \mathrm{E}_{\mathrm{i}} \mathrm{T}_{\mathrm{r}}^{\prime}
$$

$$
\begin{gathered}
r^{2} \frac{d^{2} F}{d r^{2}}+r \frac{d F}{d r}-F=-r^{2} E_{i} \alpha_{i} \frac{T_{0}}{(b-a)} \\
F=C_{1} r^{1}+C_{2} r^{-1}+A_{i} r^{2}
\end{gathered}
$$

It is obtained. Using the boundary conditions $r=a$ for case $r=a$ and $\sigma_{r}=0, r=b$ for case $\sigma_{r}=0$ the integration constants, $\mathrm{C}_{1}, \mathrm{C}_{2}$ and the final term $\mathrm{Ai}$ are determined as follows: Radial and tangential stresses,

$$
\begin{aligned}
& \mathrm{A}_{\mathrm{i}}=\frac{\mathrm{E}_{\mathrm{i}} \alpha_{\mathrm{i}} \mathrm{T}_{0}}{3(\mathrm{~b}-\mathrm{a})} \\
& \mathrm{C}_{1}=-\mathrm{A}_{\mathrm{i}}\left(\mathrm{a}^{2}+\mathrm{a} * \mathrm{~b}+\mathrm{b}^{2}\right) /(\mathrm{b}+\mathrm{c}) \\
& \mathrm{C}_{2}=\mathrm{A}_{\mathrm{i}}\left(\mathrm{a}^{2} \mathrm{~b}^{2}\right) /(\mathrm{a}+\mathrm{b}) \\
& \sigma_{\mathrm{r}}=\mathrm{C}_{1}+\mathrm{C}_{2} \mathrm{r}^{-2}+\mathrm{A}_{\mathrm{i}} \mathrm{r}=\frac{\mathrm{F}}{\mathrm{r}} \\
& \sigma_{\theta}=\mathrm{C}_{1}-\mathrm{C}_{2} \mathrm{r}^{-2}+2 \mathrm{~A}_{\mathrm{i}} \mathrm{r}=\frac{\mathrm{dF}}{\mathrm{dr}}
\end{aligned}
$$

is found as, $\mathrm{u}$ : radial displacement is obtained as in (17) below;

$$
\left(U_{r}\right)_{i}=\left(\frac{C_{1} r\left(1-v_{i}\right)}{E_{i}}-\frac{C_{2}\left(1-v_{i}\right)}{r E_{i}}+\frac{A_{i} r^{3}\left(3-v_{i}\right)}{E_{i}}+\alpha_{i} r T\right) i
$$




\section{EXPERIMENTAL RESULTS}

In this study, SiC-6061 Al alloy composite and $\mathrm{Al}-7075$ discs $15^{\circ} \mathrm{C}, 30^{\circ} \mathrm{C}, 45^{\circ} \mathrm{C}, 60^{\circ} \mathrm{C}, 75^{\circ}$ with the stresses occurring at temperatures of displacements that occur in the radial direction were analyzed. The mechanical properties of the discs in the study are given in Table 1.

Table 1. Mechanical properties of discs [13-14].

\begin{tabular}{cccc}
\hline \hline Properties & Unit & $\begin{array}{c}\text { Value } \\
\text { SíC/6061 } \\
\text { Al alloy } \\
\text { composite }\end{array}$ & $\begin{array}{c}\text { Value } \\
\text { AL - 7075 }\end{array}$ \\
\hline \hline Youngs Modulus & $\mathrm{GPa}$ & 254 & 71.7 \\
$\begin{array}{c}\text { Poisson's ratio } \\
\text { Coefficient of thermal } \\
\text { expansion }\end{array}$ & $1 / 1$ & 0.13 & 0.33 \\
\hline \hline
\end{tabular}

Radial-tangential stresses and radial displacements formed in discs are given in Table 2 .

Table 2. Stresses and radial displacements in discs.

\begin{tabular}{|c|c|c|c|c|c|c|}
\hline \multicolumn{7}{|c|}{ Radial Displacement } \\
\hline Material & Radius & $15^{\circ} \mathrm{C}$ & $30^{\circ} \mathrm{C}$ & $45^{\circ} \mathrm{C}$ & $60^{\circ} \mathrm{C}$ & $75^{\circ} \mathrm{C}$ \\
\hline $\begin{array}{l}\text { SİC/6061 Al alloy } \\
\text { composite }\end{array}$ & 20 & -0.0059 & -0.0118 & -0.0177 & -0.0237 & -0.0296 \\
\hline AL - 7075 & 20 & -0.0124 & -0.0248 & -0.0372 & -0.0496 & -0.062 \\
\hline $\begin{array}{l}\text { SİC/6061 Al alloy } \\
\text { composite }\end{array}$ & 40 & -0.0476 & -0.0952 & -0.1429 & -0.1905 & -0.2381 \\
\hline$A L-7075$ & 40 & -0.0988 & -0.1976 & -0.2964 & -0.3953 & -0.4941 \\
\hline \multicolumn{7}{|c|}{$\begin{array}{l}\text { Tangential Stress } \\
\end{array}$} \\
\hline Material & Radius & $15^{\circ} \mathrm{C}$ & $30^{\circ} \mathrm{C}$ & $45^{\circ} \mathrm{C}$ & $60^{\circ} \mathrm{C}$ & $75^{\circ} \mathrm{C}$ \\
\hline $\begin{array}{l}\text { SİC/6061 Al alloy } \\
\text { composite }\end{array}$ & 20 & -19.698 & -39.395 & -59.093 & -78.791 & -98.489 \\
\hline AL - 7075 & 20 & -12.368 & -24.737 & -37.105 & -49.473 & -61.841 \\
\hline $\begin{array}{l}\text { SİC/6061 Al alloy } \\
\text { composite }\end{array}$ & 40 & 19.698 & 39.395 & 59.093 & 78.791 & 98.489 \\
\hline$A L-7075$ & 40 & 12.368 & 24.737 & 37.105 & 49.473 & 61.841 \\
\hline \multicolumn{7}{|c|}{ Radial Stress } \\
\hline Material & $\begin{array}{l}\text { Radius } \\
\end{array}$ & $15^{\circ} \mathrm{C}$ & $30^{\circ} \mathrm{C}$ & $45^{\circ} \mathrm{C}$ & $60^{\circ} \mathrm{C}$ & $75^{\circ} \mathrm{C}$ \\
\hline $\begin{array}{l}\text { SİC/6061 Al alloy } \\
\text { composite }\end{array}$ & 20 & 0 & 0 & 0 & 0 & 0 \\
\hline$A L-7075$ & 20 & 0 & 0 & 0 & 0 & 0 \\
\hline $\begin{array}{l}\text { SİC/6061 Al alloy } \\
\text { composite }\end{array}$ & 40 & 0 & 0 & 0 & 0 & 0 \\
\hline$A L-7075$ & 40 & 0 & 0 & 0 & 0 & 0 \\
\hline
\end{tabular}

SiC-6061 Al Alloy Composite the tangential stress that occurs on the disc is shown in Figure 2 below. As the temperature increases from the chart, tangential stress values also increase. Tangential stresses in discs exposed to constant temperature were obtained as compression stress in the inner region of the 
disc and tensile stress in the outer region. The value of tangential stresses formed on the inner. Surface of the disc is higher than the tangential stresses formed on the outer surface of the disc

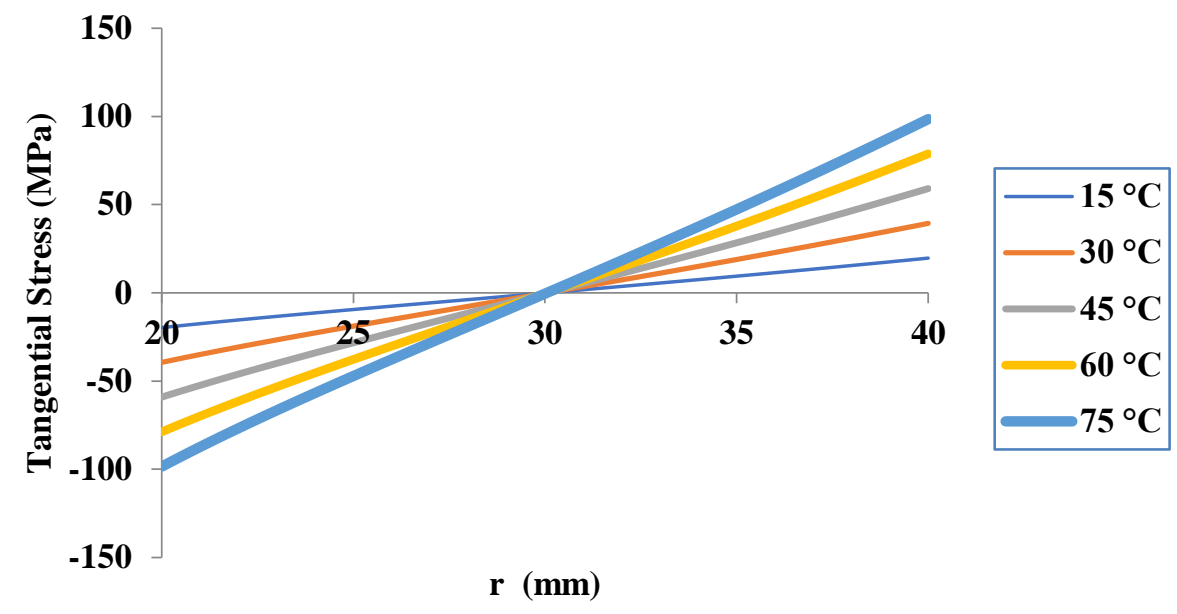

Figure 2. SiC-6061 tangential stress on disc with Al Alloy composite material.

SiC-6061 the radial stress on the disc with Al Alloy composite material is shown in Figure 3.

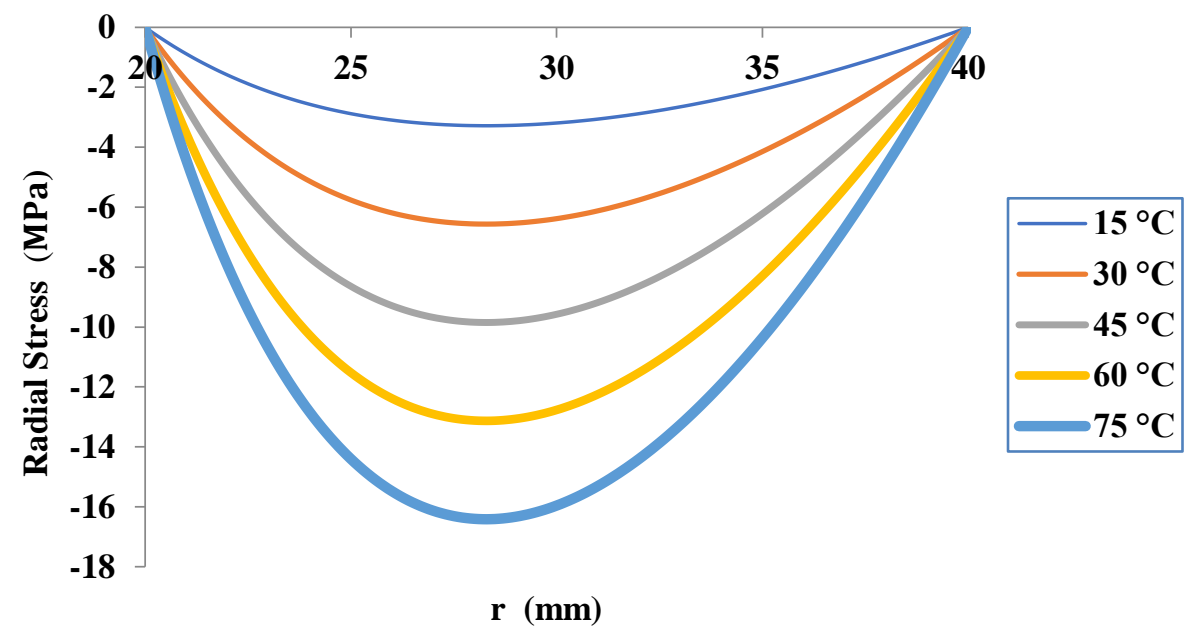

Figure 3. SiC-6061 radial stress on disc with Al Alloy composite material.

The radial displacement in the disc with SiC-6061 Al Alloy composite material is shown in Figure 4.

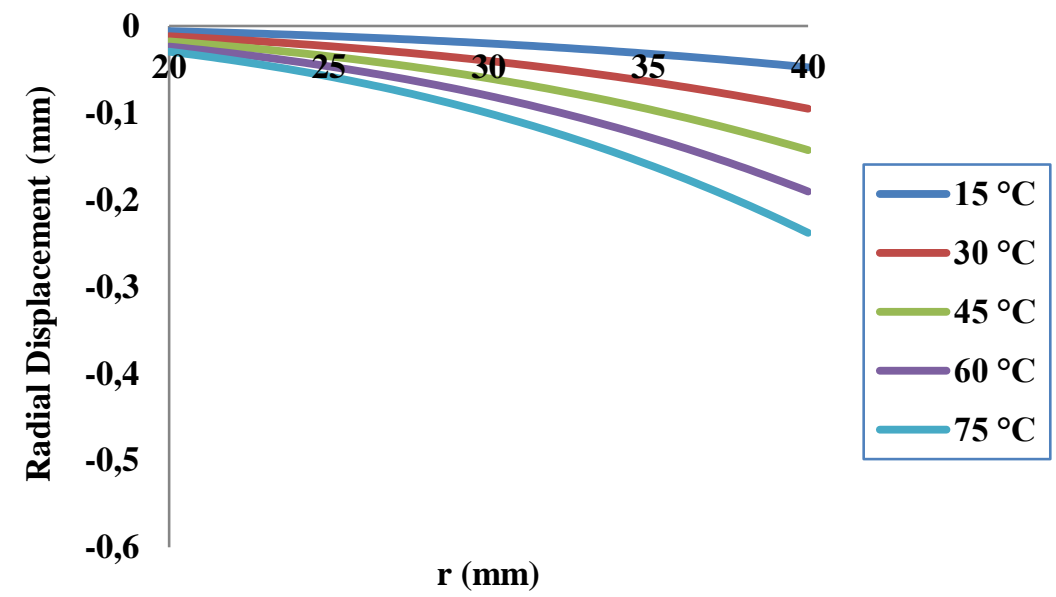

Figure 4. SiC-6061 AL Alloy composite material displacement. 
The radial displacement in the AL-7075 material disc is given in Figure 5.

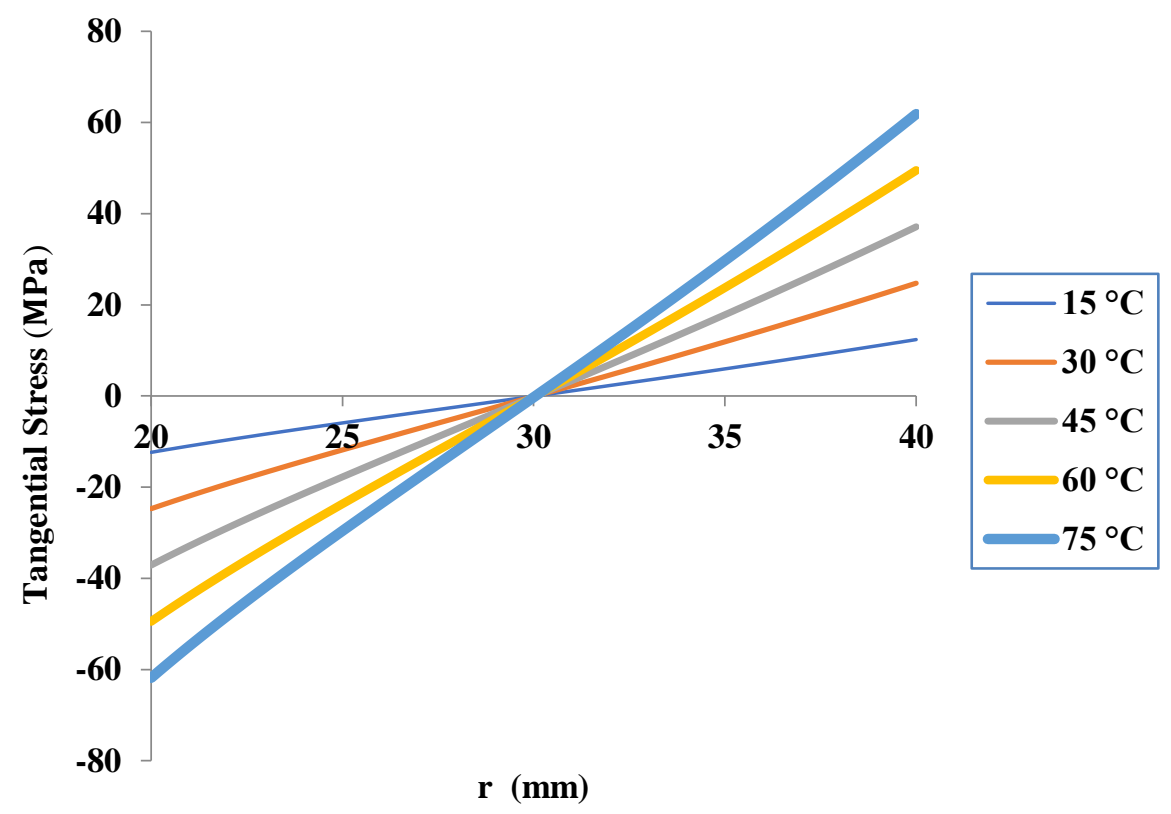

Figure 5. Tangential stress occurring in the AL-7075 material disc.

The tangential displacement occurring in the AL-7075 material disc is given in Figure 6.

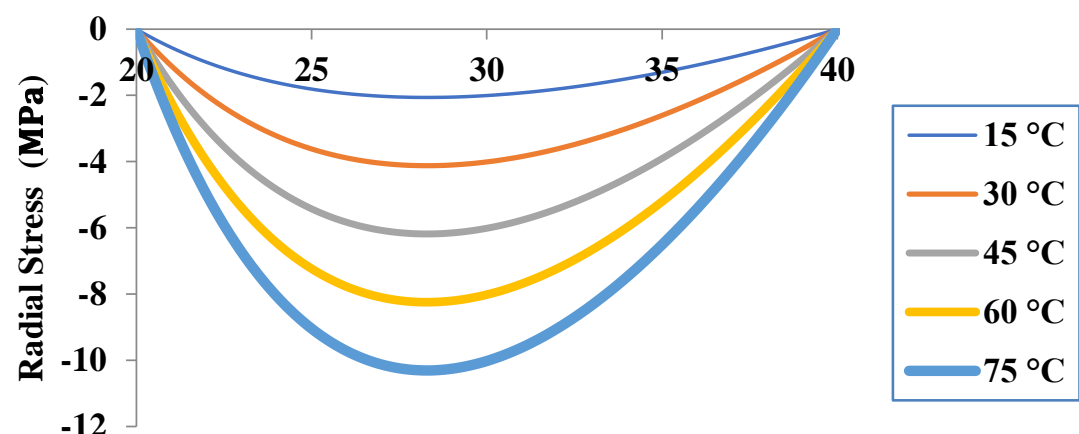

$\mathbf{r}(\mathbf{m m})$

Figure 6. Radial stress occurring in disc with AL-7075 material.

The radial displacement in the disc with AL-7075 material is given in Figure 7

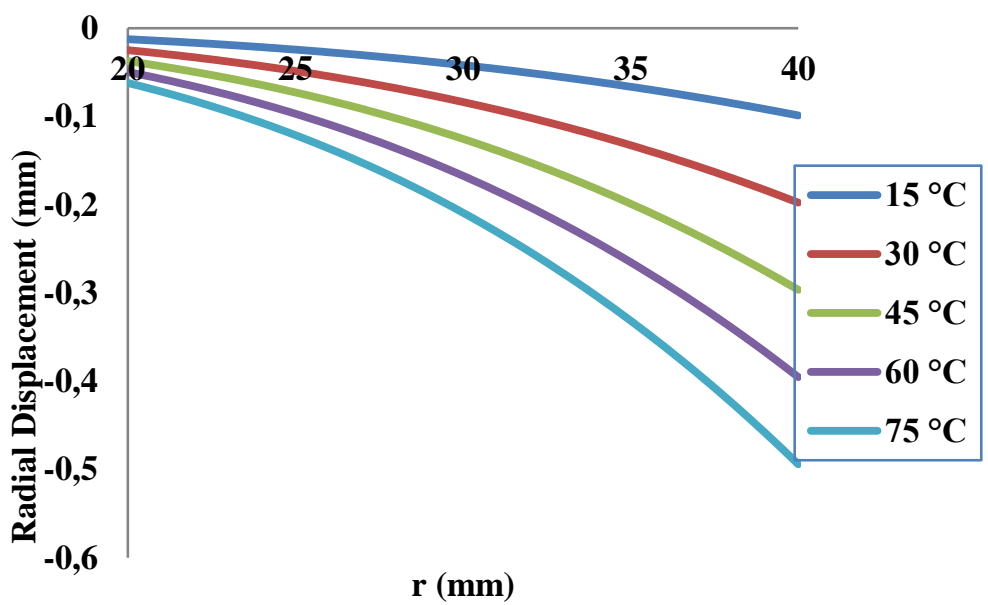

Figure 7. Al-7075 material on the disc displacement occurring. 
Figure 8 shows the displacements that occur on the inside of the discs.

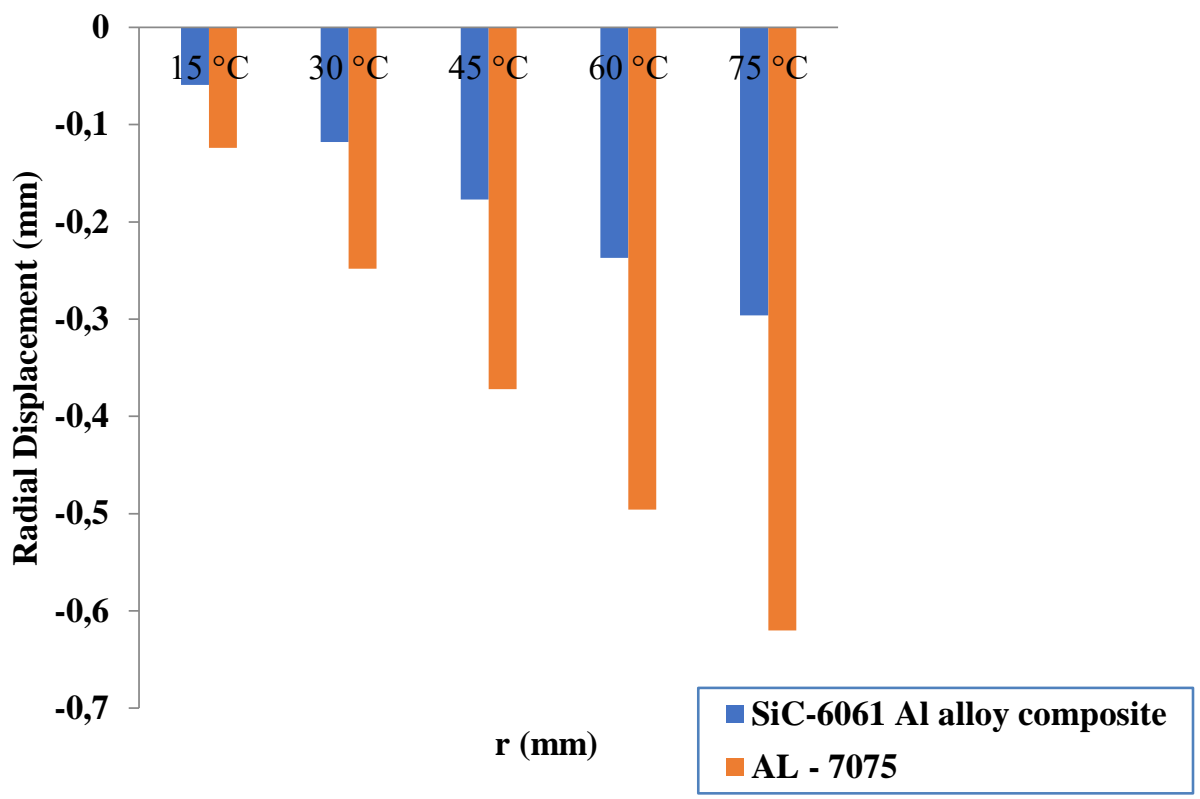

Figure 8. Displacements that occur in the inner part of the discs.

Figure 9 shows the displacements that occur on the outside of the discs.

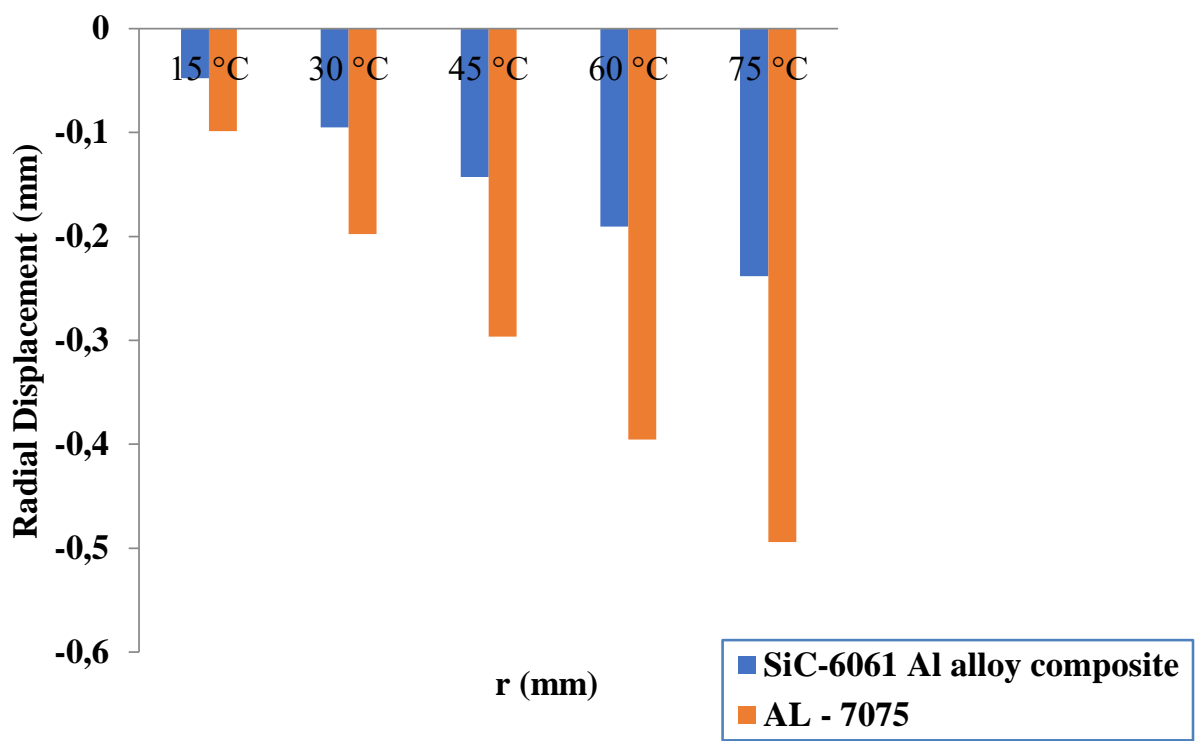

Figure 9. Displacements that occur in the outer part of the discs.

As can be seen in Figure 2 and Figure 3, the tangential stress was $-19.698 \mathrm{MPa}$ on the inner surface of the disc for a temperature of $15^{\circ} \mathrm{C}$, while $19.698 \mathrm{MPa}$ was obtained as a tensile stress on the outermost surface. For a temperature of $75{ }^{\circ} \mathrm{C}$, the tangential stress on the innermost surface of the disc was 98.489 MPa, while the tangential stress on the outermost surface was $98.489 \mathrm{MPa}$ as a tensile stress. As can be seen in Figure 5 and Figure 6, the tangential stress was $-12.368 \mathrm{MPa}$ on the inner surface of the disc for a temperature of $15^{\circ} \mathrm{C}$, while $12.368 \mathrm{MPa}$ was obtained as a tensile stress on the outermost surface. For a temperature of $75^{\circ} \mathrm{C}$, the tangential stress on the innermost surface of the disc was $61.841 \mathrm{MPa}$, while the tangential stress on the outermost surface was obtained as a tensile stress of $61.841 \mathrm{MPa}$.

In Figure 4 and Figure 7 above, the displacements in the radial direction are shown in graphs. The SiC$6061 \mathrm{Al}$ Alloy composite disc has a radial displacement of $-0.0059 \mathrm{~mm}$ on the inside of the disc at 15 ${ }^{\circ} \mathrm{C}$, while the radial displacement of $-0.0476 \mathrm{~mm}$ on the outside. At $15^{\circ} \mathrm{C}$, the AL-7075 disc has a radial displacement of $-0.0124 \mathrm{~mm}$ on the inside of the disc, while the radial displacement of $-0.0988 \mathrm{~mm}$ on 
the outside. For example, at $75{ }^{\circ} \mathrm{C}$, the radial displacement of the inner part of the SİC-6061 Al Alloy composite disc was $-0.0296 \mathrm{~mm}$, while the displacement of the inner part of the Al-7075 disc was $0.0620 \mathrm{~mm}$. At the same temperature, $\mathrm{SiC}-6061 \mathrm{Al}$ Alloy composite for radial displacements formed for the outer regions of the discs was $-0.2381 \mathrm{~mm}$, and AL-7075 for radial displacements formed on the outer part of the disc was $-0.4941 \mathrm{~mm}$. In a study of discs, the stresses formed in the disc under temperature effect were investigated by analytical and finite element method.

When determining the materials of the disc, the outer part is hard, and the elasticity modules are selected in order to select materials with $210 \mathrm{GPa}$ and the inner part is brittle $196 \mathrm{GPa}$. As a result, radial stresses increase as the temperature increases; zero in the innermost and outermost regions of the disc. As the temperature increased, tangential stresses increased at $20{ }^{\circ} \mathrm{C}$ temperature $-22.93 \mathrm{MPa}, 140{ }^{\circ} \mathrm{C}$ temperature-160.52 MPa was observed. The results obtained at the end of this study are similar. Similarly in both studies, displacement values increase as temperature increases. Because the disc materials are different, it was concluded that the resulting stress values are different from each other [15]. in a different study, he examined the behavior of discs consisting of copper and nickel alloys under thermal load by analytical and numerical analysis. In the inner regions of the disc, the radial stress components are in the form of pressure.

Maximum radial stresses were determined near the central region of the disc according to $\mathrm{R}$ values.It has been concluded that the displacements that are minimal on the inner surface are maximum on the outer surface of the disc. The disc expands outward under thermal load. The results obtained are similar to the results obtained in this study [16].

In another study, they determined thermal stresses at $60{ }^{\circ} \mathrm{C}, 90{ }^{\circ} \mathrm{C}, 120{ }^{\circ} \mathrm{C}, 150{ }^{\circ} \mathrm{C}, 180{ }^{\circ} \mathrm{C}, 210{ }^{\circ} \mathrm{C}, 270$ ${ }^{\circ} \mathrm{C}$ in a metal matrix composite disc with uniform temperature applied. Finite element method was used for analysis. Similar results were obtained with this study. It has been observed that thermal stresses, thermal shapeshifters and displacements vary depending on the different temperature changes applied [17].

Figure 10 shows the representation of the disc modeled in the ANSYS finite element program.

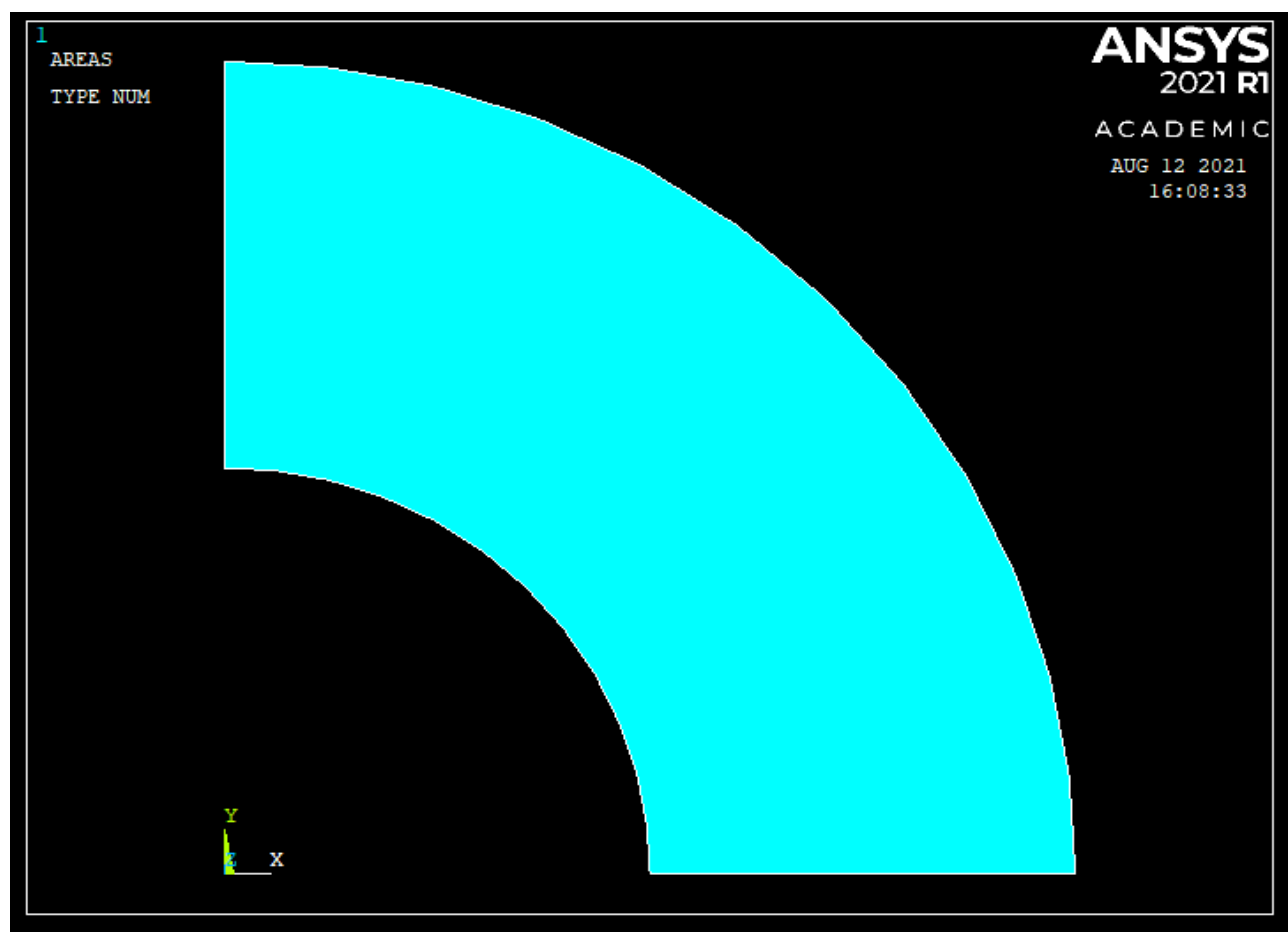

Figure 10. Disc modeled on the ANSYS 2021 R1 Academic program. 
Figure 11 shows the tangential stresses occurring on the SiC/6061 Al alloy composite disc in the ANSYS program.

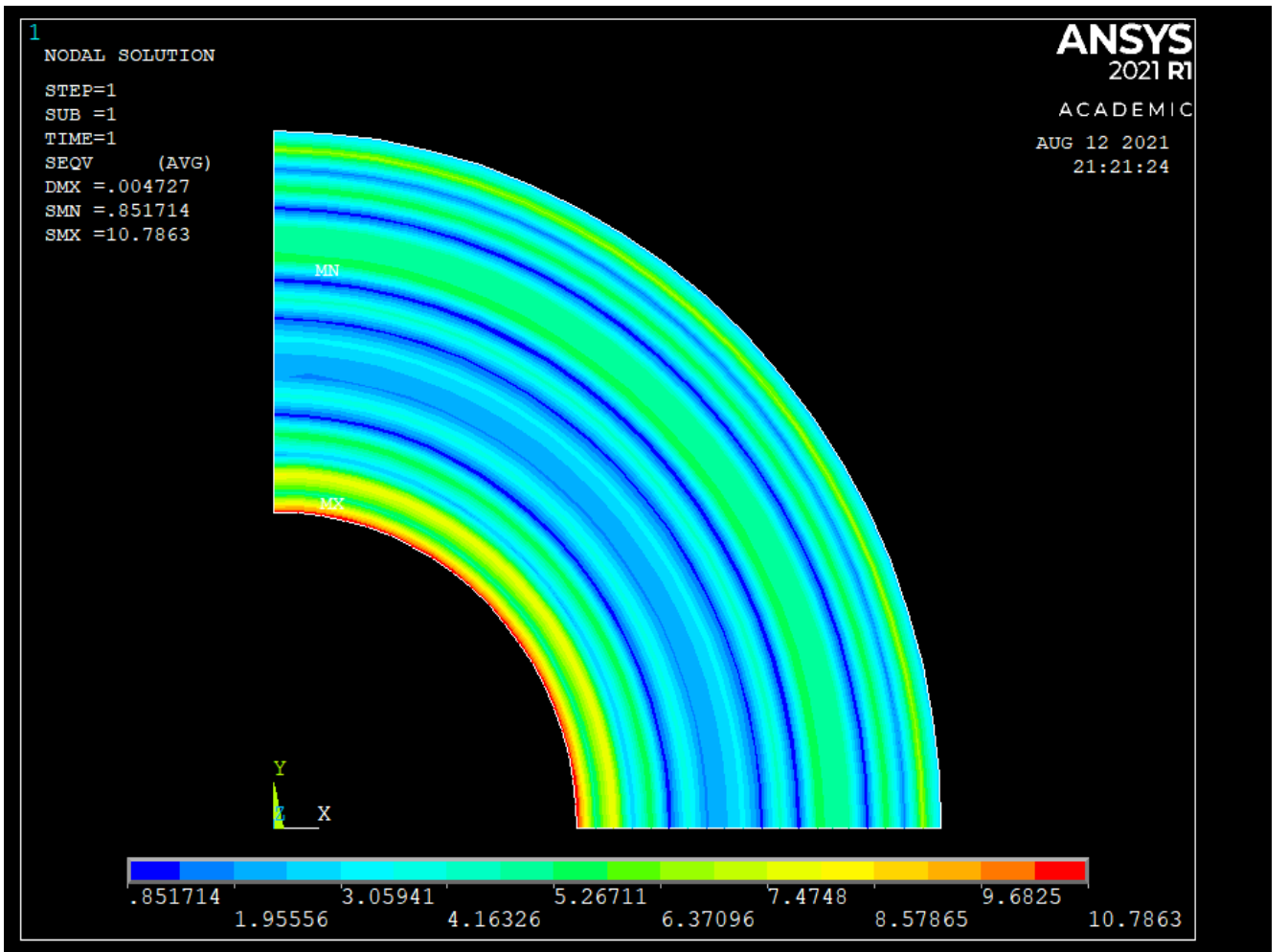

Figure 11. Tangential stresses were obtained from ANSYS Code (SiC / $6061 \mathrm{Al}$ alloy composite).

In Figure 12. SiC / $6061 \mathrm{Al}$ alloy composite a representation of radial displacements occurring on the disc is given in the ANSYS program.

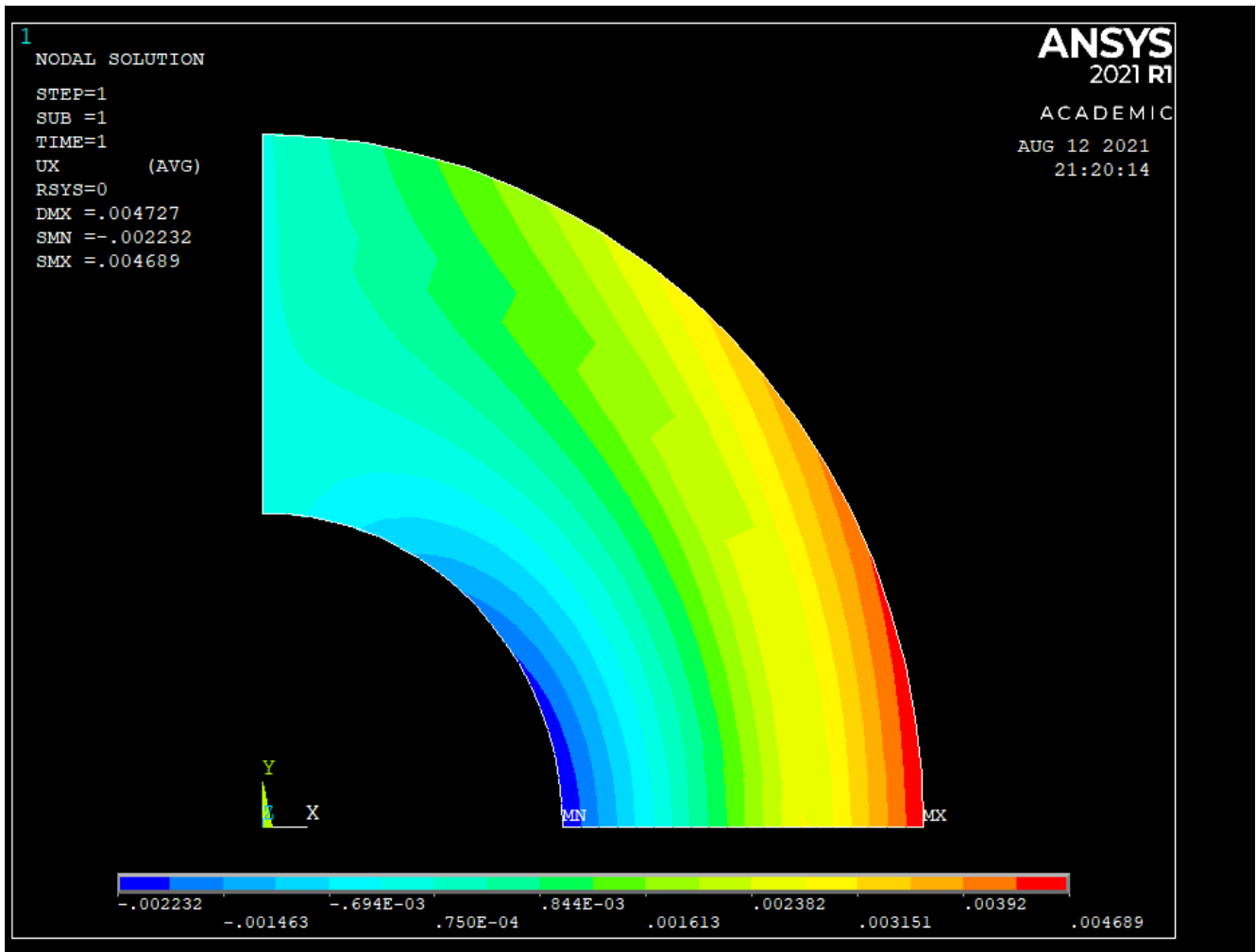

Figure 12. Radial displacement was obtained from ANSYS Code ( $\mathrm{SiC} / 6061 \mathrm{Al}$ alloy composite)

Figure 13 shows the tangential stresses occurring in the AL-7075 disc in the ANSYS program. 


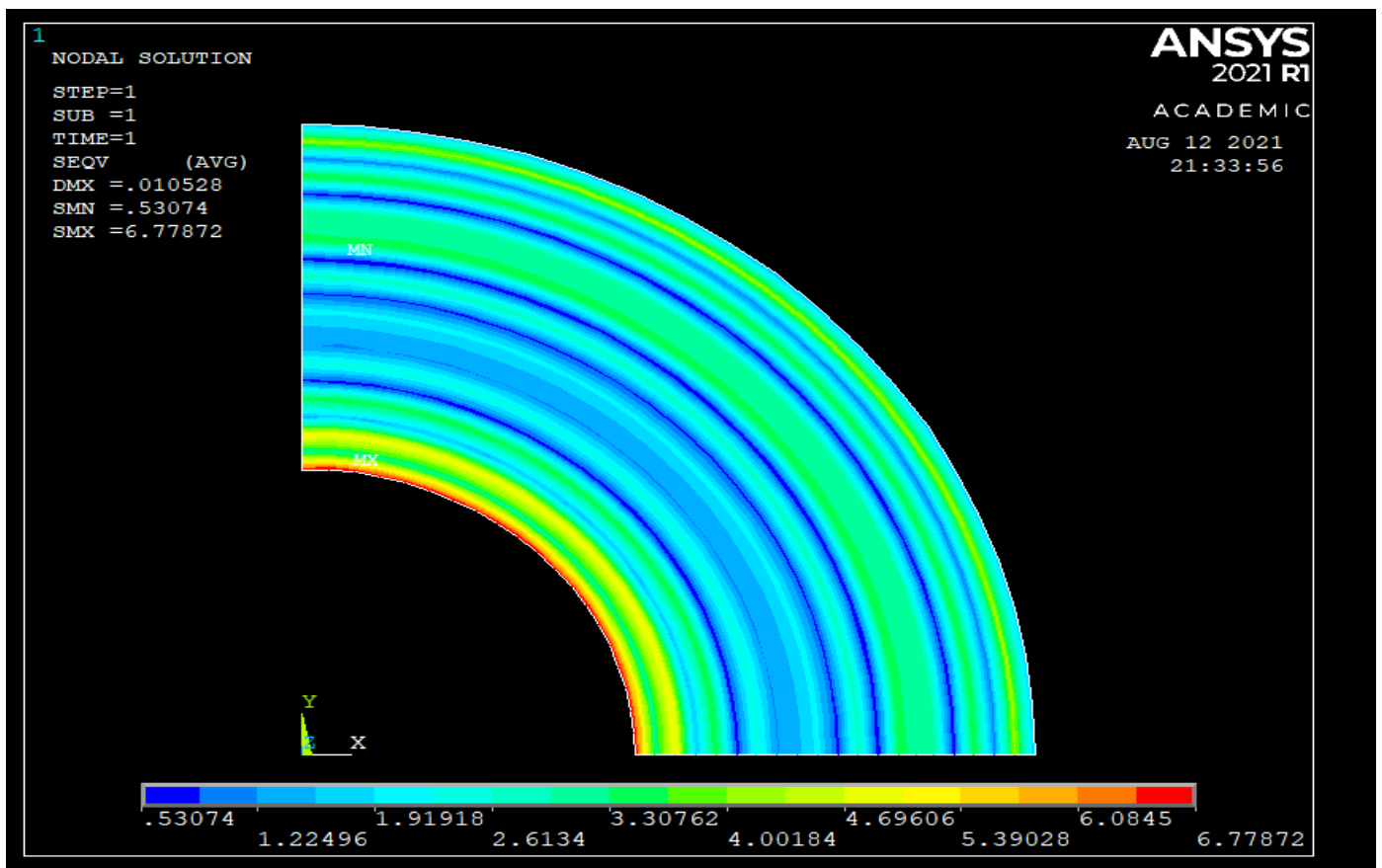

Figure 13. Tangential stresses were obtained from ANSYS Code (AL-7075).

In figure 14. AL-7075 a representation of the displacements occurring on disc is given in the ANSYS program.

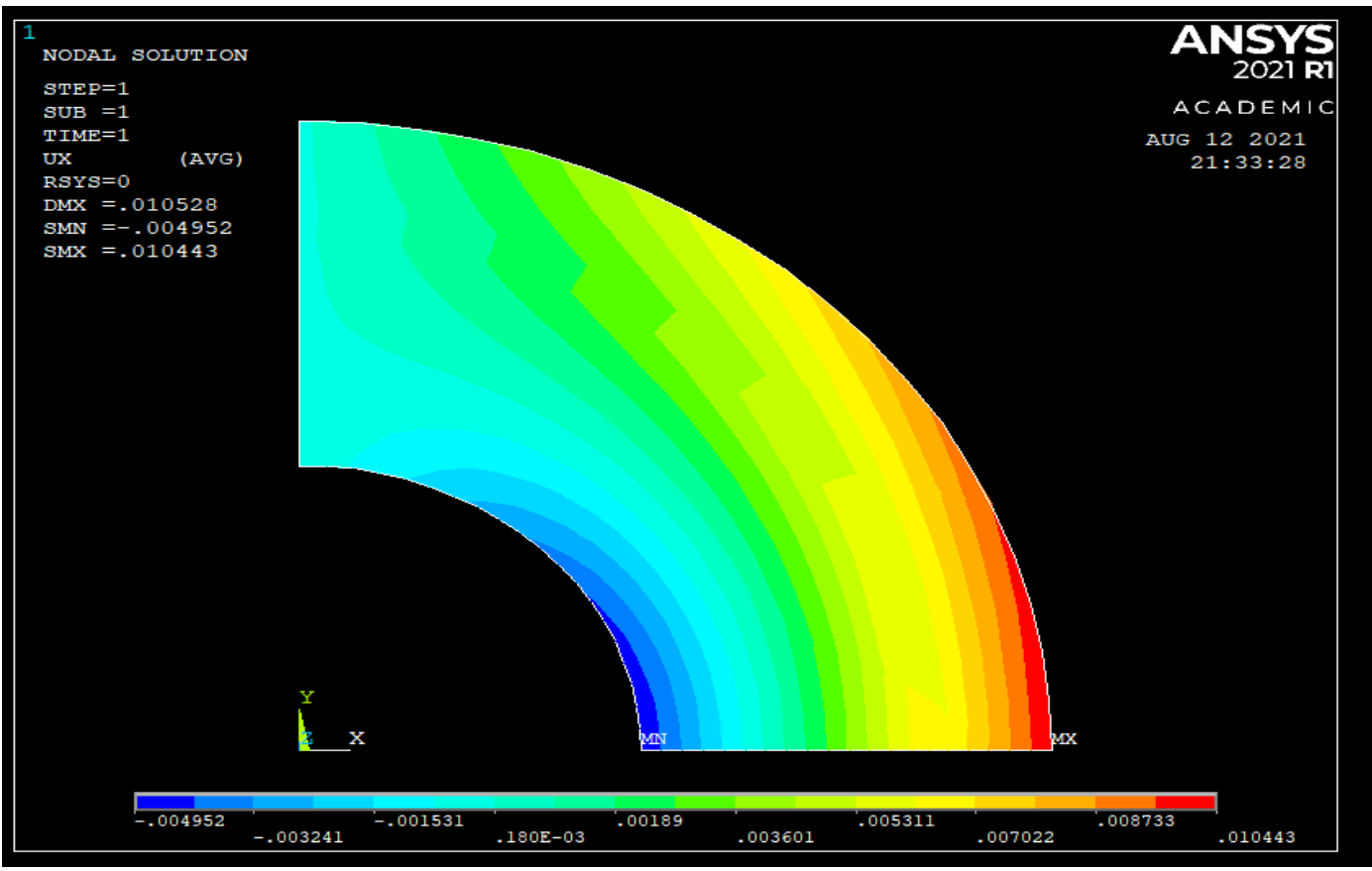

Figure 14. Radial displacement was obtained from ANSYS Code (AL-7075).

In a different study, displacements occurring in discs at temperatures of $30{ }^{\circ} \mathrm{C}-45^{\circ} \mathrm{C}-60{ }^{\circ} \mathrm{C}-75^{\circ} \mathrm{C}-90$ ${ }^{\circ} \mathrm{c}-105^{\circ} \mathrm{C}$ were investigated by the numerical and finite element method (ANSYS) program. The temperature increases linearly from the inner region of the disc to the outer part. It is modeled as disc materials $\left(\mathrm{B}_{4} \mathrm{C}\right)$, silicon carbide $(\mathrm{SSiC})$, silicon nitride $\left(\mathrm{Si}_{3} \mathrm{~N}_{4}\right)$ and carbon glass fiber. As a result, the radial displacement in silicon carbide ( $\mathrm{SSiC}$ ) material is $24.9 \%$ greater than in silicon nitride $\left(\mathrm{Si}_{3} \mathrm{~N}_{4}\right)$. Carbon glass fiber disc displacement was found to be $32.9 \%$ greater than Tungsten carbide (WC). For example, the displacement in the innermost region of the designated discs is $0.052 \mathrm{~mm}$ in tungsten carbide (WC) material, $0.105 \mathrm{~mm}$ in boron carbide $\left(\mathrm{B}_{4} \mathrm{C}\right)$ material, $0.050 \mathrm{~mm}$ in silicon carbide $(\mathrm{SSiC})$ 
material, $0.040 \mathrm{~mm}$ in silicon nitride $\left(\mathrm{Si}_{3} \mathrm{~N}_{4}\right)$ material, $0.069 \mathrm{~mm}$ in carbon glass Fiber material, respectively. Displacements in the outermost region of the discs, respectively; $0.410 \mathrm{~mm}$ in tungsten carbide (WC) material, $0.831 \mathrm{~mm}$ in boron carbide $\left(\mathrm{B}_{4} \mathrm{C}\right)$ material, $0.397 \mathrm{~mm}$ in silicon carbide $(\mathrm{SSiC})$ material, $0.317 \mathrm{~mm}$ in silicon nitride (Si3N4) material, $0.545 \mathrm{~mm}$ in carbon glass fiber material. When the temperature increases linearly from the inner part of the disc to the outer part, the displacement that occur in the disc are determined in the direction of pulling. In this study, the temperature from the inner region of the disc to the outer part is applied as constant. The resulting displacements were obtained in the direction of printing. Both studies showed that as the temperature increased, displacements increased, and more displacement occurred in the outermost region of the discs. [18]

\section{CONCLUSION}

In this study, thermal stress analysis was performed analytically under constant temperature distributions for two different discs consisting of SiC-6061 Al Alloy Composite and AL-7075. For different temperature values, radial and tangential stress components occurring from the inner surface of the disc to the outer surface were calculated. For conditions in which the modulus of elasticity does not change with temperature, the distributions of radial and tangential stresses occurring in the region from the inner surface of the disc to the outer surface were examined.

As the temperature increases, the displacements occurring in the radial direction increase. A significant change in radial and tangential stresses has been observed since the materials of the discs differ in elasticity modules and thermal expansion coefficients. If the temperature is constant from the inner surface of the disc to the outer surface, radial stresses are formed as a pressure stress. Tangential stresses occurred in the form of a pressing stress from the innermost part of the disc to the Middle Region, and in the form of a pulling stress from the middle part to the outer region.

With the increase in temperatures, stress values also increase. The tangential stresses occurring on the SIC-6061 Al alloy composite disc are greater than the tangential stresses occurring on the Al-7075 disc. For example, $15{ }^{\circ} \mathrm{C} \mathrm{SiC}-6061 \mathrm{Al}$ alloy composite the tangential stress on the inner surface of the disc is $59.26 \%$ higher than the tangential stress on the Al-7075 disc. Radial stresses in the SIC/6061 al alloy composite disc are greater than radial stresses in the Al-7075 disc for example; the stress in the $\mathrm{R}=38$ $\mathrm{mm}$ region of the disc at $15^{\circ} \mathrm{C} \mathrm{SiC}-6061 \mathrm{Al}$ alloy composite disc is $59.38 \%$ greater than the stress in the Al-7075 disc. It has been observed that displacements from the inner part of the discs to the outer part have increased in the radial direction. The results were found to be consistent with other studies published in the literature. The radial displacements occurring on the Al-7075 disc are greater than the radial displacements occurring on the $\mathrm{SiC}-6061 \mathrm{Al}$ alloy composite disc. For example, the displacement on the inner surface of the disc at $15^{\circ} \mathrm{C} \mathrm{Al}-7075$ is $110.16 \%$ greater than the tangential stress on the SiC6061 al alloy composite disc.

According to the results obtained at the end of the analysis; in order to reduce displacement; it is believed that the availability of a disc with SiC-6061 Al alloy composite material in disc design may be appropriate. The results obtained using the ANSYS 2021 R1 Academic program were similar to those obtained numerically. At the end of this article, it is believed that the SIC/6061 Al alloy composite material can be used on discs, suitable for using machines that require high temperatures and the $\mathrm{AL}$ 7075 material can be used at more brittle and low temperatures.

\section{REFERENCES}

1. Kumar, R.S., Lawrence, D., Jayabal, S., "Characterization of particulate reinforced aluminium 7075-TiB-2 composites", International Journal of Civil Engineering and Technology, Vol. 8, Issue 9, Pages 178-190, 2017.

2. Horgan C., Chan A., "The stress response of functionally graded isotropic linearly elastic rotating discs", Journal of Elasticity, Vol. 55, Issue 1, Pages 219-230, 1999.

3. Güllü, E., Pala, Y., “Analysis on rotating disc with constant surface velocity”, Pamukkale University Journal of Engineering Sciences, Vol. 6, Issue 1, Pages 39-45, 2000. 
4. Kayıran, H.F., "Boron-carbide $\left(\mathrm{B}_{4} \mathrm{C}\right)$ thermal stress analysis of a disc", 2nd International Mediterranean Symposium, Pages 47-65, Mersin, 2019.

5. Kayıran, H.F., "Investigation of thermal stress behavior of discs with different diameters of aluminum (al2024- t3) boron carbide $\left(\mathrm{B}_{4} \mathrm{C}\right)$ ", 4th International Mediterranean Symposium, Pages 81-98, Mersin, 2020.

6. Kayıran, H.F., "Investigation of elastic tensile behavior of thermoplastic discs reinforced with steel wires", Journal of Intelligent Systems and Applications, Vol. 3, Issue 2, Pages 73-76, 2020.

7. Boğa, C., Yıldırım, V., "Direct application of the complementary functions method (CFM) to the static analysis of rotating discs with both parabolic-varying thickness profile and functionally graded (fg) material", Research on Engineering Structures and Materials, Vol. 3, Issue 1, Pages 11-25, 2017.

8. Dimitoka, K., Lightning B., "Calculation of thermal stresses in thermal barrier coatings made of layered and functional graded materials by finite element method", Journal of Engineers and machines, 19(3), 81-98, 2003. Vol. 19, Issue 3, Pages 81-98, 2017.

9. Jahed, H., Shirazi, R., "Loading and unloading behaviour of a thermoplastic disc", International Journal of Pressure Vessels and Piping, 78(9), 637. Vol. 78, Issue 6, Pages 37-45, 2017.

10. Ozdemir, A.," Determination of fracture toughness values of ceramic materials by three-dimensional finite element method", Dokuz September University, Izmir, 2006.

11. Hassani, A., Gholami, M., "Analytical and numerical bending solutions for thermoelastic functionally graded rotating discs with non-uniform thickness based on Mindlin's theory", Journal of Stress Analysis, Vol. 2, Issue 1, Pages 35-49, 2017.

12. Timeshenko, S., Goodier, J.N., "Theory of elasticity”, Pages 77-90, McGraw-Hill, New York, 1970.

13. Farayibi, P.K., Akinnuli, B.O., Ogu, S., "Mechanical properties of aluminum-4043/nickel coated silicon carbide composites produced via stir casting", International Journal of Engineering Technologies, Vol. 4, Issue 1, Pages 41-46, 2018.

14. Auger, P.," Production and characterization of 7075 aluminum alloys", Y1ldız Technical University, İstanbul, 2011.

15. Çallığlu, H., Karakaya, P., "Thermal back analysis of a stratified disc", Journal of electronic machine technologies, Vol. 5, Issue 1, Pages 61-68, 2008.

16. Ersan, Ç., "Thermal stress analysis in functionally graded discs”, Pamukkale University, Denizli, 2008.

17. Sen, F., Akyuz, B., "Analysis of thermal stresses in metal matrix composite rotating disc in shallow effect", Journal of Engineering of Dicle University Faculty of Engineering, Vol. 4, Issue 1, Pages 51-60, 2013.

18. Kayıran, H.F., "Numerical analysis of displacements in circular discs applied with different materials", Asia Mathematica, Vol. 5, Issue 1, Pages 168-177, 2021. 